\title{
Challenges of Teaching Statistics to EFL Undergraduates: Action Research
}

\author{
Kusumarasdyati \\ English Department, Universitas Negeri Surabaya, Indonesia \\ kusumarasdyati@unesa.ac.id
}

\begin{abstract}
The present paper reports the challenges that the researcher had when teaching statistics to undergraduates majoring in the teaching of English and how to overcome them. It attempted to describe: (1) how to increase their motivation to learn statistics, and (2) how to improve their ability in statistical analysis. Approached qualitatively and quantitatively, this study was conducted by using mixed-method action research. The research subjects consisted of forty-one undergraduates attending the Quantitative and Qualitative Analyses class in the English Department, and were selected purposively. Data were collected by means of these instruments: participatory observations, exercises, focus group discussions and a statistics test. The results indicated that setting clear instructional goals and relating statistics to the undergraduates' study and future duties in the teaching profession could increase their motivation to learn statistics. To improve their ability in statistical analysis, it was better for them to avoid using software immediately to analyze numbers; rather, they should learn to compute numbers manually while at the same time trying to find out what each term meant and how to interpret the results. Based on these findings, some implications for the teaching of statistics to the EFL undergraduates were described.
\end{abstract}

Keywords- Statistics; language teaching; EFL

\section{INTRODUCTION}

Teachers of English as a foreign language (EFL) inevitably employ statistical formulas - albeit simple ones-in their practice because they have to assess the learners' language proficiency by means of tests. Although some other instruments are available to measure how much the learners have improved their language proficiency, such as observation, journals, portfolios [1], it is generally agreed that tests remain the main tool in classroom assessment. To date, tests have been considered an accurate technique to measure constructs in language learning such as speaking proficiency, vocabulary knowledge, grammar competence and reading comprehension $[2,3]$ by eliciting the learners' behaviors related to those constructs [4]. Most educational institutions, consequently, require teachers to report the learners' linguistic performance in the form of test scores or grades. Obtaining numerical data from the tests, the teachers have to analyze these numbers to find out the average of scores in a particular class, the relative position of a learner (above, on or below average) in that class, the dispersion of scores in that class, and the difference between scores obtained from different classes. Such an analysis invariably needs statistical formulas so the teachers have to possess the ability to utilize the formulas.

For this reason, the English Department of Universitas Negeri Surabaya (UNESA) offers the compulsory course Quantitative and Qualitative Analyses to the undergraduates studying in the Teaching English as a Foreign Language (TEFL) study program. These pre-service teachers learn statistics to analyze numeric data in the first half of the semester, then they attempt to analyze qualitative data in the form of words in the second half. The latter is beyond the scope of this paper so in the rest of the paper the course Quantitative and Qualitative Analyses refers to the former only. The objectives of this course are twofold: to equip the pre-service teachers with basic knowledge about statistics and to enable them to use the statistical formulas related to language teaching and learning. The materials include types of scales (nominal, ordinal, interval and ratio), central tendency (mode, median and mean), variability (range and standard deviation), correlation (Pearson $r$ and Spearman $r$ ) and the difference between means ( $t$ test) [5]. By learning the concepts of statistics and the computation, they will be able to not only assess their students quantitatively, but also conduct quantitative research on TEFL in thesis writing near the end of their study and in the in-service stage after graduation.

Unfortunately, many pre-service teachers showed lack of motivation in learning statistics in the above course. Some of them asked why they had to learn to compute when they enrolled in TEFL study program to gain knowledge about language pedagogy. Some others preferred to be quiet but apparently they were disengaged with learning in the classroom. They looked uninterested, did not do the exercises and most of the time responded to the lecturer's questions with silence. Consequently, they performed poorly in most computation tasks although it has been made more efficient by the use of software. In this course, they computed numeric data by means of Microsoft Excel. This software was selected for two reasons, i.e. it contained all the formulas that the preservice teachers needed to use and was already installed in the device of all pre-service teachers. Whereas computing 
numeric data became more convenient for them due to the technology, it did not make the quantitative analysis easier, as shown in their low ability to interpret the results of the computation. They could obtain numbers from the computation but they hardly understood what these numbers meant.

These two challenges, lack of motivation and poor performance in computational tasks, caused great concern because they hindered the achievement of the learning objectives. Therefore, the present study was conducted to describe: (1) how the motivation of the EFL pre-service teachers to learn statistics could be increased, and (2) how their ability in statistical analysis could be improved. In the next section, the methodology will be elaborated to provide a detailed account of the procedures in conducting the research. Afterwards, the results of the research and the discussion will be presented, and at the end of this paper the conclusions will be drawn.

\section{METHOD}

Approached quantitatively and qualitatively, this study was action research conducted to overcome the challenges [6] that the researcher faced while teaching statistics at the beginning of 2016. The subjects consisted of forty-one sophomores taking the course Quantitative and Qualitative Analyses at the TEFL Study Program in the English Department, and were selected purposefully due to the problems of low motivation and ability in completing computation tasks.

To collect data from them, four instruments were used, namely, participatory observation, focus group discussions, exercises and a statistics test. In the observation, the researcher acted as the lecturer in the classroom when monitoring the subjects' motivation to learn statistics. She recorded any behaviors and utterances that indicate their levels of motivation in field notes. Additionally, she gave a written exercise in every session to find out the improvement of the subjects' ability in statistical analysis. Later, focus group discussions were carried out with the subjects for two purposes: to validate the results of observation and to elicit information about their improvement from their own perspectives. Finally, a paper-based statistics test was administered in the middle of the semester as the mid-term exam, which gave insight into the subjects' ability in using statistical formulas and interpreting the values.

The data collection began in the third session after the problems were identified in the first and second sessions. It ended in the seventh session, then in the eighth session they sat for a mid-term exam. After the data had been collected, they were analyzed in three stages: (1) familiarizing and organizing, (2) coding and reducing, and (3) interpreting and representing [7].

\section{RESULTS AND DISCUSSION}

The interventions occurring from the third until the last sessions indicated that the effective solutions to lack of motivation to learn statistics included setting clear instructional goals and involving the subjects in collecting and analyzing numeric data to make the pre-service teachers realize why they had to understand the concepts about statistics and possess computational skills. To improve their ability in analyzing numeric data, the use of software was delayed until the final session. Instead, the subjects had to compute manually while attempting to understand the statistical concepts. These findings will be elaborated below.

\section{A. Increasing the Motivation to Learn Statistics}

In the previous section it was mentioned that the root of the problem in motivation was the subjects' failure to see the reasons for learning how to compute numeric data. The most important step in overcoming this challenge was elucidating the instructional objectives so the subjects became insightful about the reasons. The objectives "to enable the learners to understand the concepts of statistics" and "to enable them to compute data in the form of numbers and analyze the results" lacked clarity because they did not explicitly state how the concepts and the skills were beneficial for them in daily practice. In such a situation the researcher played an essential role in providing a link between what the subjects learned in the classroom and what they would do with it in the real life. The researcher explained to them that these skills would be indispensable when they became teachers and had to evaluate their pupils, the materials or some programs. In addition, they had to write a thesis before graduating from the university, and the computation skills would be very helpful if they conducted quantitative research for the thesis. This explanation provided a strong ground for the subjects to learn statistics and made them realize the importance of taking the compulsory course. As a consequence, their motivation began to increase, as shown in their enthusiasm and better engagement during the lectures.

To boost their motivation further, the researcher demonstrated the application of the statistical formulas in the real contexts. Initially, some quantitative research reports about various topics from academic journals were presented to arouse their interest. To enhance their understanding about the statistical analysis in the research, they participated in data collection and statistical analysis as a part of quantitative study conducted by the researcher. In a session about correlation, for instance, the lecture began with an amusing example of a correlational study that found a positive relationship between chocolate consumption and the number of Nobel laureates in twenty-two countries [8]. A detailed explanation about the concepts of correlation from the researcher followed, then she asked them to take part in data collection of a correlational study about the relationship between the readability from the lecturer and the students' perspectives. They read five reading texts and rated the difficulty level from 1 (the most difficult) 
to 5 (the easiest), and so did the researcher. From this activity, two sets of scores were obtained and analyzed by means of Pearson Product Moment, resulting in a negative, very high correlation ( $r=-.98)$ [9]. Table 1 details the readability from the perspective of both and the correlation coefficient

\section{TABLE I. CORRELATION BETWEEN PREDICTED AND ACTUAL} READABILITY

\begin{tabular}{|l|c|c|c|c|}
\hline Topic of the Texts & $\begin{array}{c}\text { Lecturer's } \\
\text { Rank }\end{array}$ & $\begin{array}{c}\text { Students' } \\
\text { Rank }\end{array}$ & $\mathbf{r}$ & \multirow{2}{*}{$\mathbf{r}_{.05}$} \\
\hline Geese & 5 & 2.05 & & \\
\hline Book & 4 & 2.34 & \multirow{2}{*}{-.98} & \multirow{2}{*}{.89} \\
\hline Landslide & 3 & 3.27 & & \\
\cline { 1 - 3 } Sitting & 2 & 3.46 & & \\
\hline Hard Times & 1 & 3.88 & & \\
\hline
\end{tabular}

Being involved in collecting and analyzing numeric data proved to be motivating because they found that it was not as complicated as they thought and that statistics proved to be useful in evaluating reading materials in language teaching.

Another example occurred in the session about central tendency. To make it easier for the subjects to understand the concepts of mode, median and mean, the researcher used their scores of the quiz administered in the previous session to illustrate the triad. In this way, the explanation that the researcher gave in the lecture became more concrete because the examples were about the subjects themselves. After gaining sufficient basic knowledge about central tendency, again they practiced collecting data by administering the Test of Vocabulary Size [10] to the freshmen, sophomores, junior students and senior students in the TEFL Study Program within one week. They submitted the scores that estimated the students' vocabulary size to the researcher, then in a session the researcher and the subjects computed the mode, median and mean together on the basis of the classes the students belonged to and the year they were in. This activity was equally motivating for the subjects. During a focus group discussion they admitted that it gave them a sense of achievement and thorough understanding about the materials.

\section{B. Improving the Ability to Analyze Numeric Data}

In the previous section it was mentioned that successful attempts to compute numbers could boost the subjects' motivation in learning statistics. On the other hand, high motivation could also increase their perseverance in doing a challenging task and eventually lead to successful learning. Rather than debating this issue as a chicken-or-egg one, in this paper it is better to consider the influence of motivation and successful learning as bidirectional.

Being highly motivated paved the way for the subjects to improve their ability in statistical analysis. However, it was not easy to accomplish because most of the basic concepts were completely unknown to them at the beginning of the course. To make it even more challenging, these concepts had to be learned in English as a foreign language instead of their second language, Bahasa Indonesia. Therefore, the researcher performed interventions to assist the subjects in learning statistics with relative ease.

First, the use of software was delayed until the last session. It hardly meant undermining the role of technology in the teaching of statistics. On the contrary, teaching computational skills could be more effective in the context of EFL teacher training when the manual calculation preceded the computerized one. There is no doubt that technology is pivotal in the teaching of statistics due to its benefits, i.e. making computations faster and more efficient [11] and yielding more accurate results. Even three decades ago Hughes [12] encouraged language teachers to utilize software in performing a statistical analysis of pupils' scores rather than computing the scores manually. Today this advice becomes increasingly relevant due to the development of technology, with the invention of online and offline applications for various devices to crunch a large amount of numeric data. It is hardly any wonder, therefore, that there have been efforts to integrate technology to the teaching of statistics, such as the Technological Pedagogical Content Knowledge (TPCK), a framework created to educate teachers to master the content knowledge and at the same time possess pedagogical and technological skills $[13,14]$. Although the use of technology is considered indispensable in statistics classes, the key issue which educators usually overlook is how to use the technology to promote learning. This problem also occurred in the statistics class in the English Department of Unesa. Teaching statistical analysis by means of Microsoft Excell without demonstrating how the numbers were obtained made the undergraduates grapple to comprehend the concepts related to the computation. This provided a strong reason to use the software only after the undergraduates were able to compute numbers manually.

Second, the undergraduates learned the statistical concepts while performing analysis manually. It is essential to note that statistics is a process which consists of planning, collecting numeric data, processing the data and interpreting the results $[15,16]$. Therefore, viewing statistics as using the software to process the data and obtain the results only is oversimplification. The software functions as a means to an end rather than the end in itself. It assists the users in the calculation, but the main aim of learning statistics is to understand the statistical concepts to enable meaningful interpretation of the results [11] so that appropriate conclusions about a particular set of data can be drawn. For beginners who knew very little about statistical concepts, machine calculation might have conveniently given them the number they needed with only a click on their device, but they had no slightest idea about how they got this number and what it meant. The unfortunate situation led to failure to do the last step in statistical analysis, i.e. interpreting the results. Taking the above problem into account, it was sensible to put 
emphasis on manual computation in the initial sessions of the statistics class.

In the interventions, which began in the third session, they learned statistical concepts by following the aforementioned steps: planning, collecting data, processing data and interpreting the results. To illustrate, they could gain good insights on the interrelated concepts of central tendency and variability by doing the aforementioned project of measuring vocabulary size. In the planning phase, the researcher explained that the undergraduates were going to find out how much vocabulary the students in the English Department on average knew, and given copies of the Test of Vocabulary Size [10] that they had to administer to the first- until the fourth-year students. They formed four groups, each of which would be responsible for administering the test to the freshmen, sophomores, junior students or senior students. Afterwards, they collected data from these students for one week and in the next session they had numeric data in the form of scores. They attempted to process the data by manually computing the mode, median, mean, range and standard deviation of each set of data. Lastly, they interpreted the results of the computation and drew conclusions about the average number of words that the students know in each level. They also found out how homogeneous or heterogeneous a particular group was from the standard deviation and how the mean contributed to the dispersion of scores because they knew that in the manual computation the mean was included in the formula of the standard deviation.

Another project had the undergraduates find out the relationship between two variables in the fifth session. As explained in the previous subsection, the purpose of the project was to describe how the readability of English texts from the lecturer's perspective correlated with that in the undergraduates' opinion. The planning phase was spent on explaining the aforementioned objective of the study and how to accomplish it. Unlike the previous project where they collected data from their peers, in this one the lecturer acted as the researcher who collected data from the undergraduates. The latter judged the readability of five English texts from the hardest to the easiest in the same session as the planning. In the next session, both the lecturer and the undergraduates manually computed the correlation coefficient together so that the undergraduates understood the whole process of the computation. They also learned some English terms related to the computation and what they meant, such as square root for akar in Indonesian. The next phase was the interpretation of data, in which they figured out what the correlation coefficient ( $\mathrm{r}=-.98$ ) meant by consulting it to the table of critical values and drawing a scattergram. Again some useful English terms were explained during the process of analyzing the data. For instance, they knew that the symbol $d f$ represented the degree of freedom or the number of scores minus one, and critical value was a value in a distribution at a point between rejection and acceptance for hypothesis testing. By understanding each concept in a step-by-step computation activity, it became easier for them to interpret the resulting numbers.

In the sixth session they learned to find out the difference between two means by using t-test, which was the last topic in the statistics class. They investigated whether the length of the sentences contributed to the readability of English texts, and to do this they had to compare two sets of scores obtained from a text in two versions: the original one with longer sentences and the one rewritten to make the sentences shorter. To collect the data, the undergraduates again served as the subjects. They learned random assignment as an essential characteristic in experimental research by assigning themselves into two groups randomly. One group read the original text, whereas the other read the modified text. Both of them answered the same comprehension questions in written form, resulting in a set of scores from each group. To analyze the data in the form scores, they utilized the t-test formula to process the numeric data manually. As in the previous session, the researcher functioned as the facilitator to assist them in completing this task while introducing each relevant term and its meaning. The computation yielded a $\mathrm{t}$ value $(\mathrm{t}=3.38)$, which they consulted with the table of critical value and found that there was a significant difference in the readability between the text containing long sentences and the text consisting of short sentences (Table 2).

TABLE II. THE RESULTS OF T VALUE COMPUTATION

\begin{tabular}{|c|c|c|c|c|c|}
\hline Readability & $\overline{\mathrm{X}}$ & $\mathrm{SD}$ & $\mathrm{df}$ & $\mathrm{t}$ & $\mathrm{t}_{.05}$ \\
\cline { 1 - 3 } High & 87.1 & 5.5 & \multirow{2}{*}{39} & \multirow{2}{*}{3.38} & \multirow{2}{*}{1.684} \\
\hline Low & 67.3 & 4.8 & & & \\
\hline
\end{tabular}

Near the end of the sessions above, the researcher conducted focus group discussions with the undergraduates to elicit how well they had performed in the statistical analysis from their perspectives and how effective the manual computation tasks were in improving their statistical knowledge and skills. The results of the discussions revealed that they felt satisfied with their performance and the manual computation effectively helped them to improve their knowledge and skills. Their opinions were consistent with the results of the exercises in the form of the projects above and the results of the researcher's observation.

TABLE III. THE RESULTS OF THE MID-TERM EXAM

\begin{tabular}{|l|l|l|}
\hline $\mathrm{N}$ & $\overline{\mathrm{X}}$ & $\mathrm{SD}$ \\
\hline 41 & 81 & 2.8 \\
\hline
\end{tabular}

After they had good understanding about the statistical concepts and skills in computations, they learned statistical analysis by using technology in the last session. The researcher demonstrated how to operate Microsoft Excel to compute the mean, the standard deviation, the correlation coefficient and the $t$ value. The undergraduates did the same in their device (a laptop or a tablet), using the data that had been 
collected from the previous sessions. Some unseen data were also given to them as additional exercises, then they had to use the software in the computation and interpret the results. The focus group discussion the researcher had with them at the end of the session indicated the undergraduates thought the stepby-step manual computation was effective to help them understand the whole process of statistical analysis and the machine computation made it more efficient. The results of the mid-term exam $(\overline{\mathrm{X}}=81)$ that they took in the following session provided evidence of their good performance, supporting their claim about their ability (Table 3 )

\section{CONCLUSION}

This paper reported the action research conducted to improve the EFL undergraduates who lack the motivation and the ability to learn statistics. To increase their motivation, interventions were done in the form of setting clear instructional goals, explaining the role of statistics in their thesis writing and the in-service practice, and project-based learning activities. In addition, the interventions to improve their ability in completing computational tasks were twofold: focusing on the manual computation to make the concepts more comprehensible and delaying the use of software until they mastered how to compute manually. These interventions proved to be effective in solving the problems of motivation and performance in statistical analysis.

From these findings, some implications for the teaching of statistics could be derived. It is essential to emphasize the importance of statistics to the undergraduates early at the beginning of the course so they understand that there is a very good reason for this course to be offered as a compulsory one to the pre-service teachers. To make this statement more meaningful, they have to be involved in the whole process of planning, collecting the data, analyzing the data and interpreting the results of the analysis, taking their interest into account. In this way, they realize how useful statistics is for thesis writing and assessing their pupils in the future. Additionally, the teaching of statistics should enlighten the undergraduates' mind as to how the formulas could be used to measure language proficiency, reading comprehension and other constructs in language learning rather than merely training the undergraduates to be the operators of statistical software such as Microsoft Excel or SPSS. It is wiser, therefore, to ensure that the undergraduates understand the concepts well and know how to use the formulas manually before they wish to speed up the computation by means of softwaret.

\section{REFERENCES}

[1] C. E. Turner, Classroom assessment In Fulcher G and Davidson F The Routledge handbook of language testing, New York: Routledge, 2012.

[2] H. D. Brown, Language assessment: Principles and classroom practices, New York: Pearson Education, 2004.

[3] D. Douglas, Understanding language testing, New York: Routledge, 2014.

[4] L. F. Bachman, Fundamental considerations in language testing, Oxford: Oxford University Press, 1995.

[5] A. E. Bartz, Statistical concepts, New York: Macmillan Publishing Company, 1998.

[6] A. Burns, Doing action research in English language teaching: A guide for practitioners, New York: Routledge, 2010.

[7] D. Ary, L. C. Jacobs, and C. K. Sorensen, Introduction to research in education, Belmont: Wadsworth, 2010.

[8] F. H. Messerli, The New England Journal of Medicine, vol. 367, pp. 1562-4, 2012.

[9] Kusumarasdyati, Proceedings of The $15^{\text {th }}$ Jogja English Teachers Association (JETA) International Conference, Yogyakarta: Universitas PGRI Yogyakarta, 2016.

[10] I. S. P. Nation and D. Beglar, The Language Teacher, vol. 31, pp. 9-13, 2007.

[11] D. Pratt, N. Davies, and D. Connor, The role of technology in teaching and learning statistics In Batanero $\mathrm{C}$, Burrill $\mathrm{G}$ and Reading $\mathrm{C}$ Teaching statistics in school mathematics - challenges for teaching and teacher education, London: Springer, 2011, pp. 97-107.

[12] A. Hughes, Testing for language teachers, Cambridge: Cambridge University Press, 2003.

[13] P. Mishra and M. J. Koehler, Teachers College Record, vol. 108, pp. 1017-54, 2006.

[14] T. Prodromou, Australian Mathematics Teacher, vol. 71, pp. 32-40, 2015.

[15] J. Marriott, N. Davies, and L. Gibson, Journal of Statistics Education, vol. 17, pp. 1-18, 2009.

[16] C. J. Wild and M. Pfannkuch, International Statistical Review, vol. 67, pp. 223-65, 2009. 